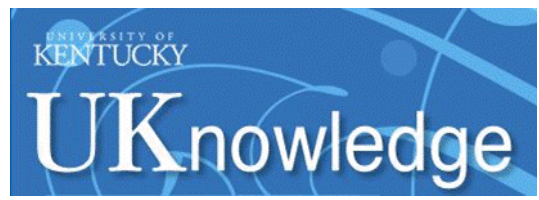

University of Kentucky

UKnowledge

\title{
Electric Aircraft System Co-Simulation Including Body, Propeller, Propulsion, and Energy Storage Models
}

\author{
Damien Lawhorn \\ University of Kentucky, damien.lawhorn@uky.edu \\ Vandana Rallabandi \\ University of Kentucky, vandana.rallabandi@uky.edu \\ Dan M. Ionel \\ University of Kentucky, dan.ionel@uky.edu
}

Follow this and additional works at: https://uknowledge.uky.edu/peik_facpub

Part of the Power and Energy Commons

Right click to open a feedback form in a new tab to let us know how this document benefits you.

\section{Repository Citation}

Lawhorn, Damien; Rallabandi, Vandana; and Ionel, Dan M., "Electric Aircraft System Co-Simulation Including Body, Propeller, Propulsion, and Energy Storage Models" (2019). Power and Energy Institute of Kentucky Faculty Publications. 22.

https://uknowledge.uky.edu/peik_facpub/22

This Conference Proceeding is brought to you for free and open access by the Power and Energy Institute of Kentucky at UKnowledge. It has been accepted for inclusion in Power and Energy Institute of Kentucky Faculty Publications by an authorized administrator of UKnowledge. For more information, please contact UKnowledge@lsv.uky.edu. 


\title{
Electric Aircraft System Co-Simulation Including Body, Propeller, Propulsion, and Energy Storage Models
}

\author{
Digital Object Identifier (DOI) \\ https://doi.org/10.1109/ITEC.2019.8790529
}

\section{Notes/Citation Information}

Published in 2019 IEEE Transportation Electrification Conference and Expo (ITEC).

(C) 2019 IEEE Copyright Notice. "Personal use of this material is permitted.Permission from IEEE must be obtained for all other uses, in any current or future media, including reprinting/republishing this material for advertising or promotional purposes,creating new collective works, for resale or redistribution to servers or lists, or reuse of any copyrighted component of this work in other works."

The document available for download is the authors' manuscript version that is accepted for publication. The final published version is copyrighted by IEEE and is available as: D. Lawhorn, V. Rallabandi, and D. M. Ionel, "Electric Aircraft System Co-simulation Including Body, Propeller, Propulsion, and Energy Storage Models," ITEC, 2019, 5p. 


\title{
Electric Aircraft System Co-simulation Including Body, Propeller, Propulsion, and Energy Storage Models
}

\author{
Damien Lawhorn, Vandana Rallabandi*, and Dan M. Ionel \\ SPARK Lab, Department of Electrical and Computer Engineering \\ University of Kentucky, Lexington, KY, USA \\ damien.lawhorn@uky.edu, vandana.rallabandi@ieee.org, dan.ionel@ieee.org
}

\begin{abstract}
This paper discusses the multi physics modeling of an electric aircraft with distributed electric propulsion. Mathematical models for the aircraft body, propellers, propulsive motors, power electronics inverters, and batteries are developed. Two types of models are proposed for the power electronics inverters and electric machines, namely, average models which allow study of the aircraft performance under a specified mission profile, and detailed switching models used for transient examination. A new simulation framework was developed to allow communication between these two types of models so that losses and thermal stresses in the power electronics converters can be estimated especially during takeoff, landing, and other extreme conditions. Case studies are presented for an example aircraft based on the ratings and configuration of X-57 Maxwell, NASA's first all-electric distributed electric propulsion electric aircraft, which employs fourteen propellers driven by synchronous electric motors.
\end{abstract}

Index Terms - Co-simulation, Distributed electric propulsion, Electric aircraft, Synchronous machines, Multiphysics.

\section{INTRODUCTION}

In the past decade, there have been several all-electric demonstrators and concept aircraft to support the progress toward electrification of flight. This paper reports the development of a simulation framework which can be used to examine the power system and flight dynamics associated with a wide array of electric and hybrid aircraft topologies. Many topological variations have emerged with respect to airplanes incorporating electric propulsion, both in the literature and flight proven vehicles. Electric aircraft may be categorized as turbo-electric, hybrid-electric or all-electric. Turbo-electric powertrains use traditional internal combustion engines (ICE) with coupled generators feeding electric machines and utilize minimal energy storage, such as NASA's N3-X [?]. Hybridelectric concepts incorporate both ICE and electric machines for propulsion and include a significant portion of energy storage. One example hybrid aircraft is the PEGASUS concept shown in [?]. In this study, an all-electric aircraft employing a distributed propulsion system with ratings similar to NASA's X-57 Maxwell [?] is used as a case study (Fig. 1). Results

* Dr. Vandana Rallabandi was with the SPARK Laboratory, ECE Department, University of Kentucky, Lexington, KY and is now with General Electric, Global Research, Niskayuna, NY. are presented for a $240 \mathrm{~kW}$ aircraft which produces thrust through 14 three-phase synchronous motors, two of which are positioned at the wing tips, with the remaining distributed along the wing. These electric machines are driven by threephase, two level inverters utilizing silicon carbide devices for high efficiency and reduced harmonic distortion. Energy storage onboard the modeled vehicle consists of Lithium-ion batteries which supply the described powertrain. Physics based models are developed for different components including the aircraft, propellers, batteries, power electronics equipment and propulsive motors. There exist many instances of cosimulation platforms being used to evaluate hybrid and electric vehicles in the literature. Work done in this area vastly covers ground transportation such as hybrid and electric cars [?], [?], [?]. However, fewer studies exist for the multiphysics domain analysis of electric air transportation. The simulation framework described in this paper includes two types of models owing to the widely different time constants of the electrical and mechanical systems, average power converter and propulsion motor models, suitable for the study of aircraft dynamics and performance over a flight profile and transient switching models, useful for determining the stresses associated with the power electronics equipment under takeoff, landing, and other similar conditions (Fig. 2). This framework has been presented with a case study of NASA's X-57 Maxwell and, in principal, can be used for detailed efficiency analysis, sizing of the thermal management system, and to study influence of switching harmonics at the system level of similar aircraft.

\section{Modeling OF AIRCRAFT DynAmics}

The dynamics associated with the body of the aircraft are simulated over a given flight profile alongside the average model of the motor and battery energy storage system. A pilot subsystem send commands to the motor model as well as flight actuation system to control air speed and altitude. The average electric machine model previously described takes in a speed command from the pilot and is coupled to the propeller model through shaft speed and associated load torque. The energy storage model uses the product of these two outputs to calculate the state of charge (SoC) of the battery throughout 
the mission. In parallel, the aerodynamic modeling receives the value of generated thrust from the propeller in addition to external forces associated with the environment and calculates the vehicle's motion. Data from this subsystem is then sensed and fed back to the pilot (Fig. 3).

Motor operating speed is dependent on the motion of the aircraft at the current state and the desired performance. As the primary focus of this study is to examine electrical performance, the vehicle geometry and aerodynamic modeling is based off of the work conducted in [?]. Considering only the $\mathrm{x}$ and $\mathrm{z}$ axes, the equations of motion for the aircraft are as follows:

$$
\begin{aligned}
& A_{x b}=\frac{d u}{d t}=\frac{F_{x}}{m}-q w-g \sin (\theta) ; \\
& A_{z b}=\frac{d w}{d t}=\frac{F_{z}}{m}+q u+g \cos (\theta),
\end{aligned}
$$

where $F_{x}$ represents the total force in the x-axis in $\mathrm{kg}, m$ is the vehicle mass in $\mathrm{kg}, q$ is the pitch angular rate, $w$ is the z-axis velocity, $g$ is the acceleration due to gravity, and $\theta$ is the pitch attitude. The force due to gravity contributes to the positive $\mathrm{z}$ direction as well as in the $\mathrm{x}$ direction. The force acting on the vehicle in the positive $\mathrm{x}$-axis is the propulsive thrust. The propulsive thrust is derived from the electric motor and propeller. The thrust is a function of the thrust coefficient, $C_{T}$, air density, $\rho$, propeller diameter, $D$, and rotational speed of the motor shaft, $n$ :

$$
F_{\text {thrust }}=C_{T} \rho D^{4} n^{2},
$$

where $F_{\text {thrust }}$ is thrust in newtons, $C_{T}$ is the coefficient of thrust, $\rho$ is the air density, $D$ is the propeller diameter in meters, and $n$ is the propeller speed in revolutions per second. where $F_{z}$ represents the total force is the z-axis and $u$ is the vehicle velocity in the $\mathrm{x}$-axis. The change in pitch angular rate is a function of the moments and the inertia:

$$
\frac{d q}{d t}=\frac{M}{I_{y y}} .
$$

\section{Modeling of Electric Propulsion System}

The propulsive force generated by the propeller is supplied from an electrical power system onboard the aircraft. The propellers are attached to twelve $10-\mathrm{kW}$ and two $50-\mathrm{kW}$ synchronous machines, supplied by means of three-phase, two-level inverters. These drives utilize advanced $\mathrm{SiC}$ power switches, capable of higher switching frequencies than traditional silicon devices, enabling a light-weight aircraft due to the reduced mass of electrical filtering. The flight profile studied in this paper covers a wide array of operating conditions including those where the power system is driven to the extremes that would be required during a typical flight plan. The combined powertrain is simulated at peak power demand during periods of takeoff when rapid acceleration of motor speed is required. Additionally, the inclusion of an emergency flight extension due to an unavailable landing runway allows endurance evaluation of the energy storage system.

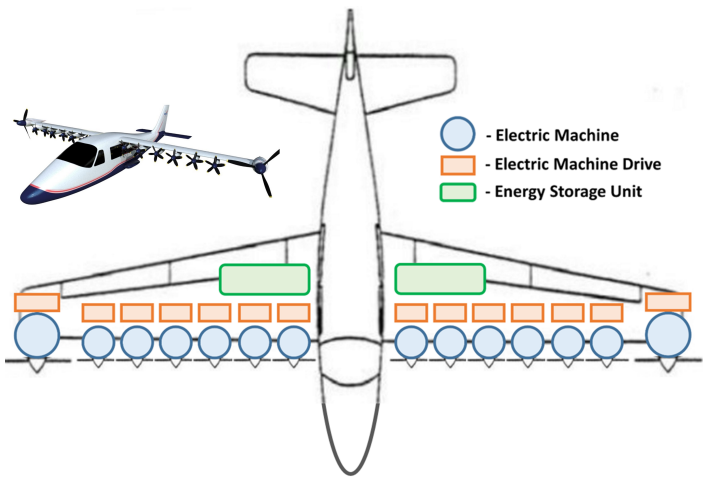

Figure 1. The X-57 Maxwell, NASA's first all-electric distributed electric propulsion electric aircraft. The new modeling software framework developed in this paper considers the aircraft power system shown with a combined total rated power of approximately $250-\mathrm{kW}$ [?], [?].

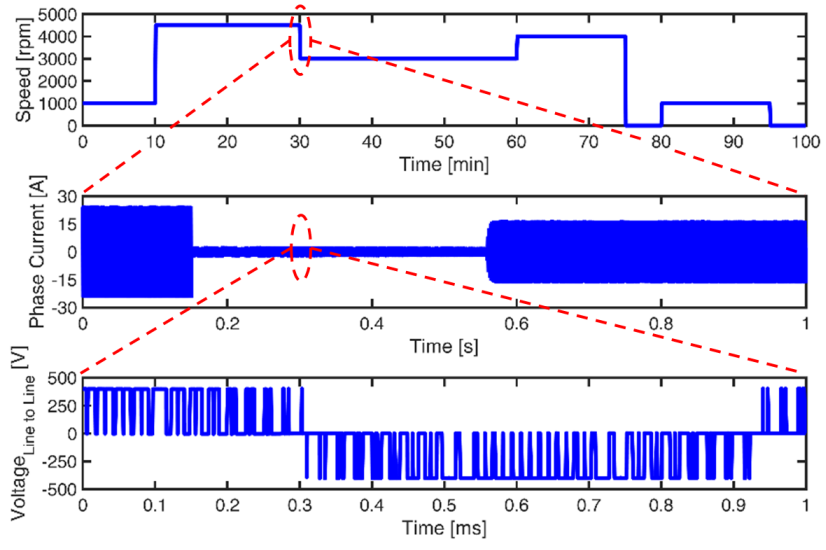

Figure 2. Illustration of the large variations in timescales between important transitions associated with each subsystem. Flight profiles may require changes in altitude over a period of minutes, leading to the need of simulating motor state transitions which occur over fractions of seconds. Additionally, the power electronics that drive the propulsion motors have associated time constants in the sub-millisecond range.

When simulating aircraft dynamics, an average model is used for evaluation of the electric motors, which is coupled to a propeller subsystem through shaft speed and load torque (Fig. 4). The synchronous machines are driven through vector control, using a dq reference frame (Fig. 5). The load torque as seen by the propeller is derived from the pilot input speed command. The acceleration of the propeller shaft is governed by the following equations:

$$
T_{M}-T_{L}=J \frac{d \omega}{d t},
$$

where $T_{M}$ is the electromagnetic torque, $T_{L}$ is the load torque produced by the propeller, $J$ is the moment of inertia of the propeller, $\omega$ is the motor's angular speed.

The load torque of the propulsion motor is that required by the propeller at a given speed. This torque can be obtained through multiplication of the output thrust and the diameter of 


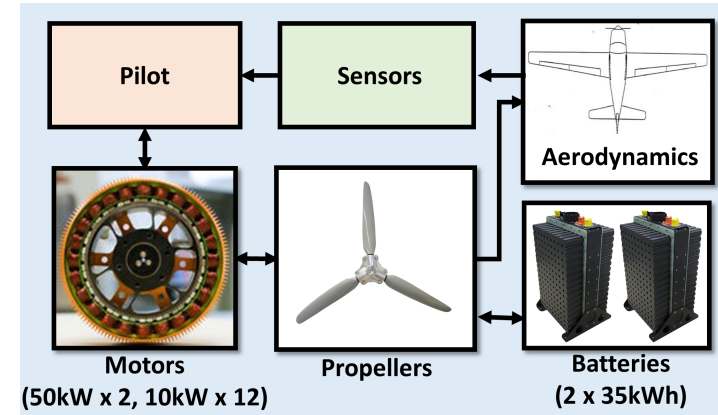

Figure 3. Electric power system and body dynamics simulation overview. The pilot controls the motors speed based on desired aircraft velocity and feedback sensor data. The motor model communicates with the propeller to obtain load torque and thrust, which used for aerodynamic modeling. The power used is employed by the battery model to determine state of charge (SoC).

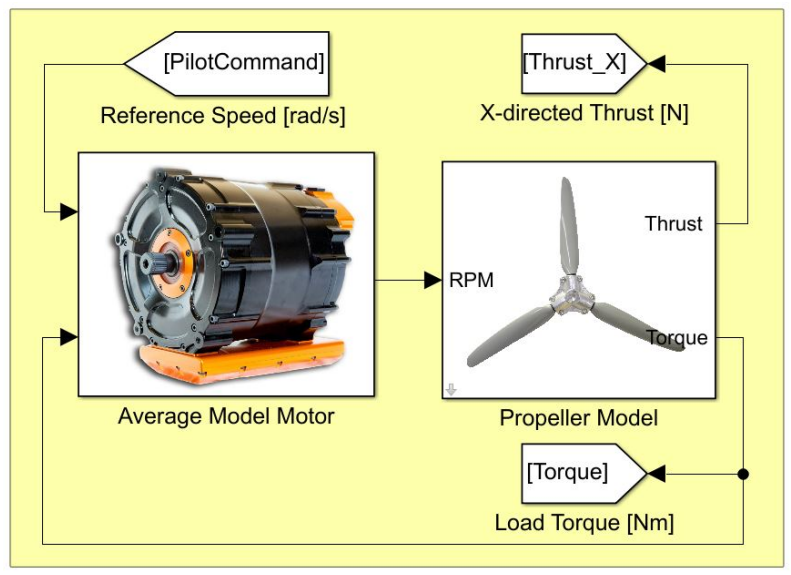

Figure 4. System level view of motor and propeller models. Motor speed is used as a control variable, commanded from the pilot. Load torque and thrust are modeled as a function of the motor speed and characteristics of the propeller. With these values, the motor model calculates instantaneous voltages and currents to achieve the demanded performance.

the propeller as well as an additional torque coefficient, $C_{Q}$ :

$$
Q=T_{L}=C_{Q} \rho D^{5} n^{2} .
$$

The values for coefficients of thrust and torque are commonly extracted from experimental data of the propeller. These coefficients are strong functions of the advance ratio, which is defined as the ratio of the true air speed and the propeller tip speed [?]. Preliminary modeling treats these coefficients as constant throughout the mission. Further analysis of propeller characteristic could include dynamic modeling of the torque and thrust coefficients through look-up tables based on interpolated manufacturer data.

The electromagnetic torque produced by the motor is a function of $p, \lambda_{m}$, and $i_{q}$ :

$$
T_{M}=\frac{3 p}{2} \lambda_{m} i_{q},
$$

where $p$ is the number of poles, $i_{q}$ is the q-axis current, and $\lambda_{m}$ is the magnetic flux linkage. In a $d q$ reference frame the

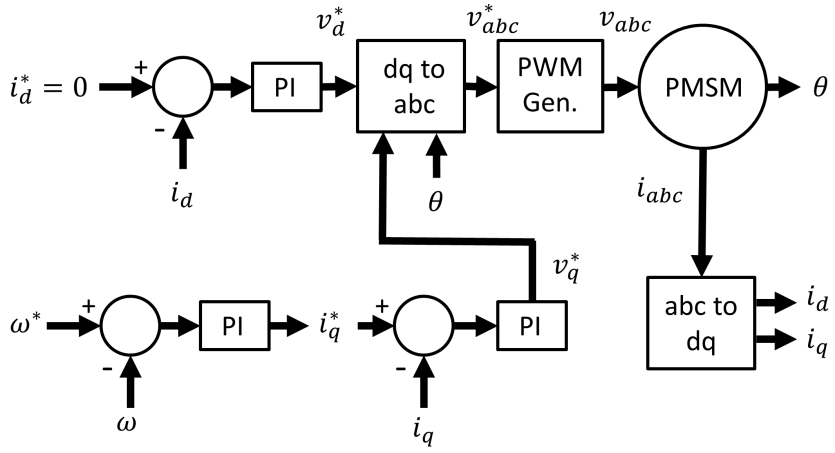

Figure 5. Control strategy for the synchronous machines providing propulsive force for the aircraft. The pilot provides the input desired speed reference and the PWM gating signals are generated for the three-phase inverter driving the machines.

demanded currents, $i_{d}^{*}$ and $i_{q}^{*}$ are defined by:

$$
i_{q}^{*}=\left(K_{p}+\frac{K_{i}}{s}\right)\left(\omega^{*}-\omega\right) ; \quad i_{d}^{*}=0,
$$

where $K_{p}$ is the proportional gain, and $K_{i}$ is the integral gain. The d-axis current command is kept at zero to ensure operation at maximum torque per ampere conditions. The output reference currents are then compared to the currents of the machine in an additional control loop to derive the following command dq voltages:

$$
\begin{aligned}
& v_{q}^{*}=\left(K_{p q}+\frac{K_{i q}}{s}\right)\left(i_{q}^{*}-i_{q}\right), \\
& v_{d}^{*}=\left(K_{p d}+\frac{K_{i d}}{s}\right)\left(i_{d}^{*}-i_{d}\right) .
\end{aligned}
$$

In the model which examines the entire aircraft system, the dynamics associated with the inverter switching characteristics are neglected. It is considered that the load torque is derived from the propeller model and the ideal voltages are applied to the motor, which is calculated using the equation below:

$$
\begin{gathered}
v_{q}^{*}=v_{q}=R i_{q}+L_{q} \frac{d i_{q}}{d t}+p \omega L_{d} i_{d}+p \omega \lambda_{m}, \\
v_{d}^{*}=v_{d}=R i_{d}+L_{d} \frac{d i_{d}}{d t}+p \omega L_{q} i_{q} .
\end{gathered}
$$

However, for periods of transition between operating speeds, the switching level model is used to evaluate maximum required rating of components.

This model also includes measures to avoid the motor operating above its rated conditions. The output speed of the motor is limited by the available DC bus voltage (11). The speed will be curtailed in the case that the demand speed requires a voltage magnitude exceeding the conditions stated below:

$$
\sqrt{V_{d}^{2}+V_{q}^{2}}<\frac{V_{D C}}{2}
$$

Without the addition of supplemental power electronics, $V_{D C}$ is the voltage of the battery energy storage system (BESS). This system constraint may be relaxed by incorporating a boost 


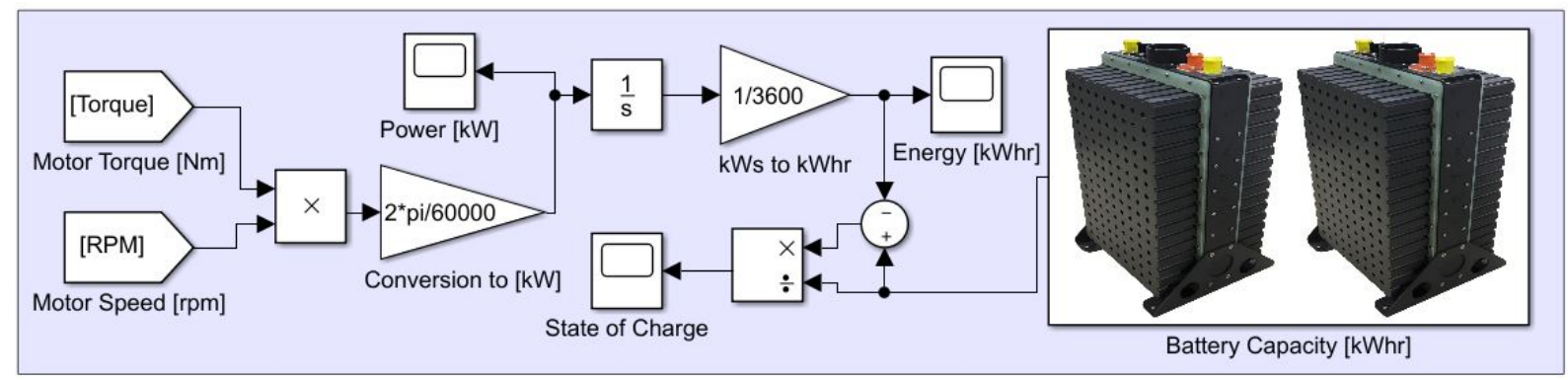

Figure 6. Simulation subsystem developed for estimating the state of charge of the battery (BESS). Inputs include battery capacity, motor torque and speed. The instantaneous power demand is calculated and integrated over time to derive the energy used over the flight cycle.

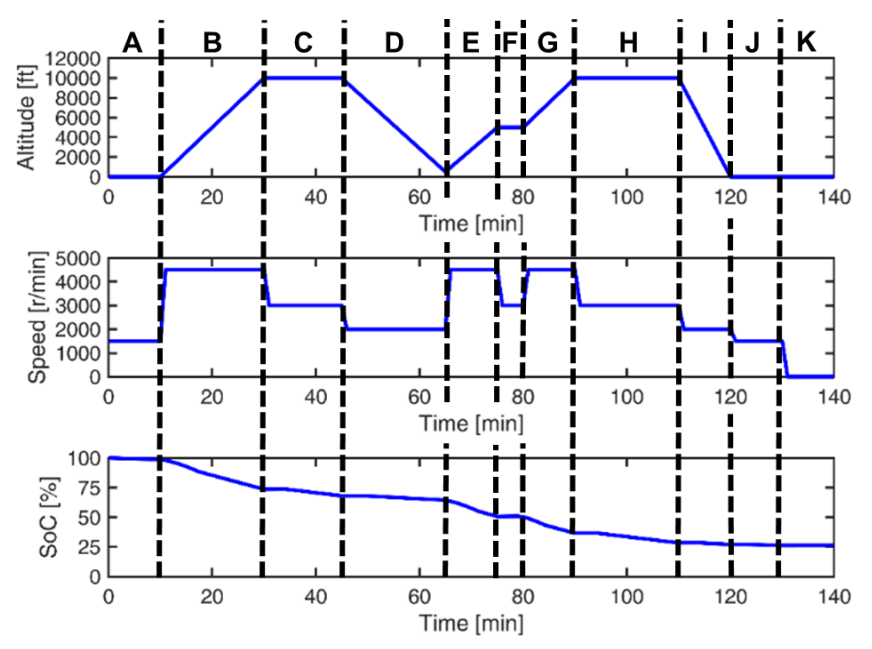

Figure 7. Example of flight profile comprising a typical mission followed by an emergency rerouting. Eleven distinct intervals are identified through letters. The graphs display the altitude, the speed of the electric motors, and the battery SoC.

stage prior to the inverter such as seen in [?].

The aircraft is supplied by a Lithium-ion BESS and supplies the propulsion system described. The usable battery capacity is considered as $47-\mathrm{kWh}$, which is similar to that seen in the $\mathrm{X}-57$ design [?]. The BESS SoC modeling is determined by integration of the combined power usage of all motors over the simulated flight cycle (Fig. 6).

\section{Simulation Results and Discussion}

The flight cycle imposed on the aircraft represents a case in which the airplane flies a typical flight path, then an emergency extension in order to model the system during extreme conditions. It is assumed that the aircraft has an initial position on the taxiway of an airport, at which point the pilot taxis to the runway and begins takeoff at $\mathrm{t}=10 \mathrm{~min}$. The aircraft is then commanded to climb to an altitude of 10,000 feet. Upon reaching the cruise level, the vehicle will maintain its altitude until $\mathrm{t}=45 \mathrm{~min}$. At this point, the airplane will start its descent for landing. The condition at $\mathrm{t}=65 \mathrm{~min}$ simulates an instance where the destination runway is unsuitable for landing, therefore the pilot must climb to a low altitude cruise and hold until a new landing location is confirmed. The aircraft then follows a climb, cruise, descent and landing pattern to the secondary destination airport from $\mathrm{t}=80 \mathrm{~min}$ to $\mathrm{t}=120 \mathrm{~min}$. The vehicle is then taxied from the runway and motors are stopped at 130 minutes (Fig. 7). The aircraft dynamics with associated average models for electric propulsion were simulated with the described flight profile. The $\mathrm{SoC}$ was observed throughout the mission and normalized with respect to the $47-\mathrm{kWh}$ usable capacity of the BESS.

Transitions between each period of the trajectory were simulated using the detailed model which considers the switching dynamics of the power electronic converters. Loading of the synchronous machines in this simulation were obtained from the model including propeller dynamics. During these periods of transition, the torque produced by the motors is varied to maintain the commanded shaft speed. Results shown include the electromagnetic torque and phase currents of a single threephase, 10-kW propulsive synchronous machine during the first four periods of flight (Fig. 8). It can be observed from the flight cycle that the maximum loading period of the power system is during the transition from periods such as $\mathrm{A}$ to $\mathrm{B}$, when the commanded shaft speed is at a maximum. These events occur when the aircraft is beginning its ramp to full power for takeoff or during a climb. Results such as the three-phase currents of a single machine from the detailed model may be used for system sizing during the initial system design stage. Applications include electric machine and power electronic converter component selection, thermal management system sizing, and potential filtering specifications required to meet signal noise goals. Additionally, these waveforms may be used to identify maximum discharge rate required for the BESS.

\section{CONClusion}

The newly developed comprehensive simulation framework for electric and hybrid aircrafts, which is described in the paper, has the main advantage of providing a unified approach for system analysis on greatly different timescales. For simulations of long-duration complete flight missions, aircraft aerodynamic models are employed in combination with average models of electric machines and power electronic converters and a proposed method for calculating the SoC of the battery, which enables the optimal sizing of the electric energy storage 

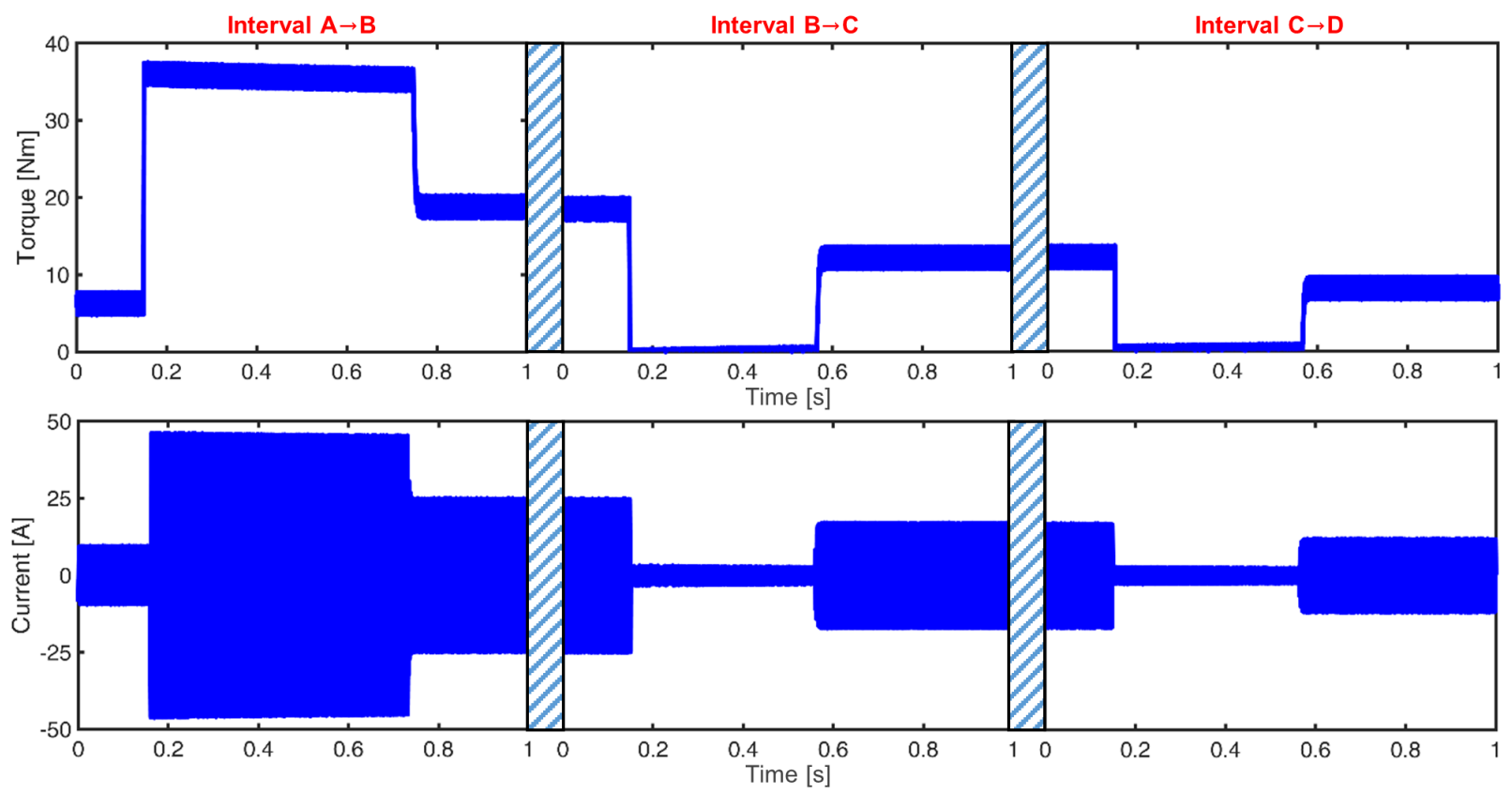

Figure 8. Electromagnetic torque produced by a single electric machine during flight phase transitions. Results from the long time constant simulation are used to evaluate the effects of the system's high frequency power electronic switching during transient periods. Speed transient conditions shown are from 1500 to $4500 \mathrm{r} / \mathrm{min}$ (left), 4500 to $3000 \mathrm{r} / \mathrm{min}$ (middle), and 3000 to $2000 \mathrm{r} / \mathrm{min}$ (right).

system. For simulations of the transitions between different steady-state intervals of the flight profile, a high resolution model of the power electronics controls was implemented to simulate the high frequency switching and the associated effects on current and voltages, in order to enable the detailed design sizing, including maximum power rating, thermal management systems and filters. The simulation framework was exemplified on an aircraft with ratings reflective of NASA's first electric airplane, the X-57 Maxwell, which is equipped with a distributed electric propulsion power system.

\section{ACKNOWLEDGMENT}

The research described in this paper is based upon work supported by NASA Kentucky under NASA award No: KY GF-19-051.

\section{REFERENCES}

[1] B. B. Choi, "Propulsion Powertrain Simulator: Future turboelectric distributed-propulsion aircraft.," in IEEE Electrification Magazine, vol. 2, no. 4, pp. 23-34, Dec. 2014.

[2] K. P. Duffy and R. H. Jansen, "Turboelectric and hybrid electric aircraft drive key performance parameters," in 2018 AIAA/IEEE Electric Aircraft Technologies Symposium (EATS), Cincinnati, OH, 2018, pp. 1-19.
[3] Y. Gibbs, "Nasa armstrong fact sheet: Nasa x-57 maxwell," Sep 2018. [Online]. Available: https://www.nasa.gov/centers/armstrong/news/ FactSheets/FS-109.html

[4] C. Irimia, M. Grovu, C. Husar, D. Fodorean and C. Antonya, "CoSimulation analysis for an electric vehicle powered by a high-speed electrical machine," in 2017 IEEE Vehicle Power and Propulsion Conference (VPPC), Belfort 2017, pp. 1-6.

[5] V. Rallabandi, D. Lawhorn, D. M. Ionel and X. Li, "Multi-Physics modeling for electric and hybrid vehicles with in-wheel electric motors," in 2018 IEEE Transportation Electrification Conference and Expo (ITEC), Long Beach, CA, 2018, pp. 146-151.

[6] Q. Zhang, N. Cui, K. Li, Y. Shang and C. Zhang, "Co-simulation of energy management strategy for hybrid electric vehicle in AVL InMotion," in emph 2017 Chinese Automation Congress (CAC), Jinan, 2017, pp. 4932-4937.

[7] A. Turevskiy, S. Gage, and C. Buhr, "Model-based design of a new lightweight aircraft," AIAA Modeling and Simulation Technologies Conference and Exhibit, 2007.

[8] A. Filippone, Z. Mohamed-Kassim, "Multi-disciplinary simulation of propeller-turboprop aircraft flight" in The Aeronautical Journal, 2012, pp. 985-1014.

[9] V. Rallabandi, D. Lawhorn, J. He, and D. M. Ionel, "Current weakening control of coreless afpm motor drives for solar race cars with a threeport bi-directional dc/dc converter," in 2017 IEEE 6th International Conference on Renewable Energy Research and Applications (ICRERA), Nov 2017, pp. 739-744. 